\title{
"La responsabilidad es nuestra": crónica y novela realista sobre prostitución en la obra de Albert Londres, Joaquín Edwards Bello y Roberto Arlt ${ }^{1}$
}

\section{"The Responsibility is Ours": Crónicas and realist novels about prostitution in the work of Albert Londres, Joaquín Edwards Bello and Roberto Arlt}

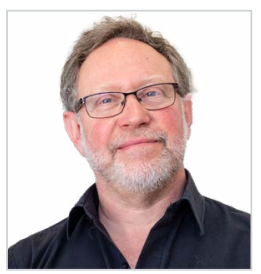

Roberto Herrscher. Periodista, escritor, profesor de periodismo. BA en Sociología, Universidad de Buenos Aires; MSc. en Periodismo, Columbia University, Nueva York. Académico de planta de la Universidad Alberto Hurtado de Chile donde dirige el Diplomado de Escritura Narrativa de No Ficción. Director de la colección Periodismo Activo de la Editorial Universidad de Barcelona, en la que se publica Viajar sola; director del Premio Periodismo de Excelencia y editor de El Mejor Periodismo Chileno en la Universidad Alberto Hurtado y maestro de la Fundación Gabo. Autor de Los viajes del Penélope (Tusquets, 2007), publicado en inglés por Ed. Südpol en 2010 con el nombre de The Voyages of the Penelope; Periodismo narrativo, publicado en Argentina, España, Chile, Colombia y Costa Rica; y de El arte de escuchar (Editorial de la Universidad de Barcelona, 2015). En 2021 publicó Crónicas bananeras (Tusquets) y su primer libro colectivo, Contar desde las cosas (Ed. Carena, España). Sus reportajes, crónicas, perfiles y ensayos han sido publicados The New York Times, The Harvard Review of Latin America, La Vanguardia, Clarín, El Periódico de Catalunya, Ajo Blanco, El Ciervo, Lateral, Gatopardo, Travesías, Etiqueta Negra, Página 12, Perfil, y Puentes, entre otros medios.

Universidad Alberto Hurtado, Chile

rherrscher@uahurtado.cl

ORCID: 0000-0001-5098-0199

Recibido: 16/09/2021 - Aceptado: 21/12/2021 - En edición: 27/12/2021 - Publicado: 01/01/2022

\section{Resumen:}

La prostitución ha sido un tema fundamental en la literatura latinoamericana, pero parece no haber surgido a la par en la crónica. Este artículo describe el lugar de la prostitución como temática en la crónica del Cono Sur en el siglo XX mediante un proceso de revisión de la obra literaria y periodística de diversos autores. Se muestra cómo, en muchos casos, los mismos novelistas (como Edwards Bello y Arlt) que escribían sus ficciones presentando el mundo prostibulario con lujo de detalles, dedicaron su copiosa producción cronística a otros temas y otros ámbitos. Además, destaca y analiza, en este contexto, el relato de no ficción El camino de Buenos Aires, de Londres, como una obra precursora en la
Received: 16/09/2021 - Accepted: 21/12/2021 - Early access: 27/12/2021 - Published: 01/01/2022

\section{Abstract:}

Prostitution has been a keysubject in Latin American literature, but itseems not to have developed the same way in crónicas. This paper describes the place of prostitution as a topic in Southern Cone crónicas in the twentieth century through a review of the literary and journalistic works of a variety of authors. The paper shows how, in many cases, the same novelists who wrote their fiction presenting the brothel and its characters with a keen eye and in precise detail (such as Edwards Bello in Chile and Arlt in Argentina) did not cover the same terrain in their copious non-fiction. Furthermore, in that context, the study highlights and analyses the literary non-fiction work The Road to Buenos Aires, by Londres, as a forerunner in

1 Este artículo forma parte del proyecto ECOS/ANID 180053: “Crónica. Comparative reportages: an ontology of French narrative journalistic influences and dialogue in Chile and Argentina", de cuyo equipo de investigación el autor forma parte.

\footnotetext{
Cómo citar este artículo:

Herrscher, R. (2022). “La responsabilidad es nuestra”: crónica y novela realista sobre prostitución en la obra de Albert Londres, Joaquín Edwards Bello y Roberto Arlt. Doxa Comunicación, 34, pp. 255-271.
}

https://doi.org/10.31921/doxacom.n34a1479 
región en términos de temática y posicionamiento del autor. Se propone que el lugar de personaje, testigo, denunciante, "responsable" del autor en la crónica periodística alejó a los escritores de tratar en su no ficción un mundo que conocían al dedillo. A la luz de la evolución de la crónica hacia finales del siglo XX, se postula que la prostitución es un asunto y una lente que nos permite entender los fundamentales cambios que se han producido en la no ficción del continente.

\section{Palabras clave:}

Crónica latinoamericana; periodismo narrativo; novela realista; prostitución; trata de blancas. the region in terms of theme and author's positioning. We suggest that the place of the crónica's authors as character, witness, accuser, and "culprit" turned writers away from addressing in their non-fiction works a world they knew all too well. In light of the development of the Latin American crónica in the second half of the twentieth century, the paper argues that prostitution is both a subject and a lens allowing us to understand the fundamental changes in non-fiction writing in the continent.

\section{Keywords:}

Latin American crónica; narrative journalism; realistic novel; prostitution; sex trade.

\section{Introducción}

Este artículo presenta el tratamiento de un tema complejo y escabroso, como es la prostitución y la trata de blancas en Argentina y Chile, en la novela y la crónica de la primera mitad del siglo XX. Aborda la limitación e imposibilidad de dos autores fundamentales en la crónica y la novela de Chile (Joaquín Edwards Bello) y Argentina (Roberto Arlt) para internarse en el burdel como narradores de no ficción y argumenta que dichas limitaciones y dificultades pueden estar relacionadas con la cercanía personal y vital de dichos autores y su cofradía intelectual bohemia como usuarios y consumidores de dichos antros. Tanto Arlt como Edwards Bello trataron infinidad de otros temas y ámbitos urbanos en sus numerosas crónicas, pero no estos asuntos prostibularios, que sin embargo eran prevalecientes en su ficción.

En contraposición, explora el tratamiento del mismo tema en el libro del cronista francés Albert Londres El camino de Buenos Aires como ejemplo cabal de periodismo narrativo con personajes reales, diálogos ciertos y descripciones fidedignas, con el uso del "yo" del narrador como testigo y protagonista de las acciones delictivas o atentatorias al derecho de las mujeres y como entrevistador de víctimas, victimarios y autoridades que no cumplen con su misión de proteger a los débiles.

El artículo propone una respuesta a la pregunta de cómo y por qué un escritor francés "de paso por Sudamérica" consigue pintar, explicar y denunciar esta lacra social en una crónica de hechos ciertos, mientras los autores locales que conocían con más profundidad ese mundo reservaron dicho tema para sus obras de ficción.

Para realizar dicha comparación, aborda como contexto el papel de la prostitución, el comercio sexual y la trata de blancas como tema en la novela realista y en el periodismo narrativo entre 1870 y 1970: sobre las diferentes formas, estrategias narrativas, creaciones de personajes, y lugares en que se coloca el narrador para abordar estos temas y estos personajes. Este trabajo parte de una constatación sorprendente: este asunto escabroso está muy presente en la novela realista de este período, en la novela social francesa y sobre todo en las obras capitales del "boom" latinoamericano, pero casi totalmente ausente en las obras de periodismo narrativo de la misma época.

Los autores de dos de las tres principales novelas de este período que tratan el tema prostibulario, el chileno Joaquín Edwards Bello (autor de El roto) y el argentino Roberto Arlt (autor de Los siete locos) son los más prolíficos cronistas a ambos lados de la cordillera de los Andes en la primera mitad del siglo XX. Estudiando los temas del inmenso número de Aguafuertes porteñas de Arlt 
y crónicas de Santiago y Valparaíso de Edwards Bello publicadas en las obras reunidas de ambos², no hay prácticamente registro del tema de las casas de lenocinio, la vida de las prostitutas y la figura del proxeneta, como revisaremos a lo largo del trabajo.

¿Por qué tantas novelas y tan pocas crónicas? Esto es especialmente notable en los casos en que los cronistas son al mismo tiempo novelistas y cuentistas. Las tristes historias de sus ficciones están casi totalmente ausentes en las obras de no ficción de los mismos autores. En cambio, la temática sí aparece en un relato de no ficción de la época, de enorme potencia, modernidad y anticipación: El camino de Buenos Aires, del viajero de denuncia francés Albert Londres.

En este artículo, nos proponemos abordar las siguientes preguntas: ¿qué lugar ocupa la prostitución en la novela social y la crónica del Cono Sur a principios del siglo XX? ¿Qué rol cumplió la crónica europea en la evolución de la prostitución en la crónica del Cono Sur durante el siglo XX? ¿Por qué estos temas, tan prevalentes en la novela de la región, no se encuentran en las crónicas de los mismos autores, y en cambio sí se presentan en El camino de Buenos Aires, una obra que en la última década ha merecido una nueva traducción, reediciones y la atención de la crítica?

\section{Métodos}

El presente estudio se propone describir el lugar de la prostitución como temática en la crónica del Cono Sur en el siglo XX. Para ello, se abordan tres objetivos específicos: comparar el lugar de la prostitución en la novela social y la crónica a principios del siglo XX en el Cono Sur; dar cuenta de la presencia de la prostitución en la novela social y crónica europea de fines del siglo XIX y principios del XX; y, por último, abordar el rol de la crónica europea en la evolución de esta temática en la crónica latinoamericana a lo largo del siglo.

Para alcanzar los objetivos descritos, este estudio realiza una revisión documental de obras literarias, críticas y periodísticas. En el caso francés, nos interesa Francia como origen del mito literario de la prostituta noble de buen corazón víctima de la pobreza y las injusticias de la sociedad, especialmente en y su papel en dos novelas fundamentales: Nana (1880/2015) de Emile Zolá y Los miserables (1862/2015) de Victor Hugo, y una obra de teatro capital: La dama de las camelias (1848/2018) de Alexandre Dumas hijo. Del lado de la crónica europea, por otra parte, se profundiza en la obra y trayectoria de Albert Londres, poeta y cronista francés que se especializó en un tipo especial de reportaje. Analizaremos especialmente su obra El camino de Buenos Aires, obra periodística que aborda la trata de personas en una época en la que, como veremos, pareciera que la crónica local no incluía dichas temáticas. En el caso del Cono Sur, nos detenemos particularmente en la obra literaria de Augusto D’Halmar y en la de Edwards Bello y Roberto Arlt, estos dos últimos exponentes de la época con un doble rol como literatos y cronistas.

A continuación, presentamos nuestra revisión. En primer lugar, se presenta la prostitución en la novela social, francesa y latinoamericana respectivamente. Luego, abordamos la crónica en Latinoamérica y Europa a principios del siglo XX. En tercer lugar, analizamos las posibilidades que ofrecían la novela social y la crónica de la época en Latinoamérica. A partir de ello, nos detenemos en la figura y la obra de Albert Londres. Por último, proveemos nuestras reflexiones e interpretaciones a partir de este ejercicio de revisión documental y contextualización de las obras.

2 Hay algunos textos del Arlt viajero que no se encuentran en los tomos de Alfaguara y las obras completas de Edwards Bello está todavía en proceso de edición en Publicaciones de la Universidad Diego Portales. 


\section{Resultados}

\subsection{La prostitución en la novela francesa}

La prostitución es uno de los temas fundamentales en las novelas realistas francesas entre mediados del siglo XIX y comienzos del XX. Tanto en las novelas de Honoré de Balzac y Emile Zolá como en la obra paralela de Charles Dickens al otro lado del Canal de la Mancha, se presenta la prostitución como el resultado de la degradación, tanto material como espiritual y psicológica, de las muchachas pobres que tienen la desgracia de resultar deseables y entran o son empujadas al mercado del sexo.

Sin embargo, desde el comienzo se muestran dos tipos muy definidos de prostituta como personaje novelístico. En un entorno cultural y moral tan dominado por la Iglesia Católica, es lógico que ambos estereotipos tengan su origen en las dos grandes figuras femeninas de la Biblia: Eva la pecadora y María la madre abnegada. Si bien hay complejidad en las construcciones literarias de estas novelas, es difícil encontrarse con personajes que escapen a la dicotomía entre la niña inocente brutalmente introducida en la "mala vida" y el de la "manipuladora de hombres", consciente del poder de su atractivo.

En el primer caso, es la imagen de una niña que pierde su inocencia, pero no su intrínseca bondad, y que para sobrevivir o alimentar a su familia vende su cuerpo como un sacrificio cuasi religioso. Así es Fantine, en Los miserables (1862/2015) de Víctor Hugo. Madre soltera de una niña concebida por un hombre sin escrúpulos a quien ella le entrega su corazón, presenta una de las características del personaje de la ramera literaria que atraviesa el siglo XIX y llega a pasada la mitad del XX: la prostituta puede ser absuelta por la prosa del autor, como Fantine; pero, para alivio de las almas puritanas de sus lectores y lectoras, siempre termina mal. Fantine trabaja en una fábrica de donde es echada por madre soltera, se extenúa prostituyéndose para alimentar a su hija pequeña, se arranca los dientes incisivos para venderlos y que su hija no pase hambre, contrae tuberculosis y muere.

De esta manera, por ejemplo, en La tentación de lo imposible, Mario Vargas Llosa tacha a Hugo de moralista porque, si bien "cae" en el pecado por necesidad, no puede dejar de sufrir durante toda su vida y hasta su muerte unas penas que hacen al autor pensar en el castigo divino: el premio Nobel peruano encuentra que, en lo referente al sexo, la moralidad de Los Miserables hunde sus raíces en la versión más intolerante y puritana del catolicismo (Vargas Llosa, 2004). Por su parte, John Andrew Frey presenta a Fantine como un ejemplo de cómo las mujeres del proletariado eran maltratadas en el siglo XIX en Francia. Fantine representa la compasión profunda por el sufrimiento humano, especialmente las mujeres que habían nacido en una posición social baja (Frey, 1999).

El otro estereotipo de la prostitución en la novela francesa es mucho más duro, aunque el personaje termina igual. Es la perversa manipuladora de hombres, la joven que desde sus inicios conoce el poder de su atractivo y su belleza y lo usa a su favor a expensas de hombres débiles; algunos, víctimas de su propia concupiscencia y otros genuinamente enamorados de la perversa. El clásico de esta mirada fascinada al mal puro de la ramera es Nana (1880/2015), de Emile Zolá, parte de una saga de 20 novelas (Les Rougon-Macquart). La estructura dramática perfecta de esta novela marca el modelo del triunfo, el descenso y el castigo final de la mujer que lleva a los hombres a la perdición. Con la astucia de quien conoce sus armas, Nana provocaba la alegría y la desazón de sus festejantes, los mataba de celos entre ellos y los hacía competir por halagarla. 
Mientras Fantine es el modelo perfecto de la María que se sacrifica generosamente por su hija, Nana, quien pasa su embarazo sometiéndose con módico dolor a un aborto porque no soporta límites a su libertad (desde el punto de vista del narrador), se abisma a su final con la fuerza de su propia energía sexual.

Nana es el modelo de la novela social de la "perdida" en América Latina. Tanto es así que los nombres de las prostitutas parisinas, y el de Nana precisamente, serán elegidos para los personajes de las meretrices locales. Una de las más célebres novelas de chicas pobres caídas en desgracia, Juana Lucero (1902), de Augusto D'Halmar, lo deja patente: en el momento en que Juana, sirvienta humillada por la patrona, abusada por el patrón y embarazada, decide entrar en un prostíbulo, se le asigna el nuevo nombre de Naná.

\subsection{El lugar del burdel en la novela social del Cono Sur}

\subsubsection{Presencia en las novelas y ausencia en las crónicas de Joaquín Edwards Bello}

En El imaginario de la prostitución en Chile: literatura y figuras arquetípicas, 1902-1940, Ana Gálvez Comandini (2013) acredita el aporte de los novelistas (todos ellos hombres) a la visión de este fenómeno en la primera mitad del siglo XX en Chile:

Los médicos y la policía señalaban en sus escritos y documentos, que era imposible erradicar una práctica social tan arraigada en la colectividad por medio de leyes y normas, y los literatos lo confirmaron, representando en sus novelas cuál era el lugar que ocupaba el prostíbulo en el imaginario y la importancia que éste tenía en la sociedad chilena de comienzos del siglo XX. La contribución de los escritores se centró, principalmente, en visibilizar por medio de la literatura prácticas sociales que habían sido relegadas a las sombras (p. 220).

La “novela de prostitución” nace en Chile precisamente con Juana Lucero, de Augusto D'Halmar, publicada en 1902, que produce un enorme revuelo social. El personaje central representa a las muchachas pobres del campo que llegan a la capital a trabajar como sirvientas y, con la fuerza de un camino de perdición que no puede evitarse, termina prostituida en un burdel de Santiago. Joaquín Edwards Bello, quien fustigaba en sus columnas los males de la clase alta y describía ambientes de lujo y de pobreza, elige el burdel como escenario de sus novelas La cuna de Esmeraldo (1918) y sobre todo El roto (1920/2019). En estos relatos se encuentra una descripción minuciosa y quirúrgica del burdel como escenografía de la degradación, mezcla de falso lujo imaginado por el pueblo llano e inmundicia. La estructura de fábula con moraleja de estas novelas abreva más en el legado de la novela realista francesa (que sus lectores conocían) que en el estilo más parco y descriptivo de sus crónicas de la época, tal como las analiza su antologador, Roberto Merino. A este respecto, Merino (2014) coloca las crónicas de Edwards Bello en el lugar de la descripción descarnada de la alta sociedad santiaguina que tan bien conoce, y sus novelas, especialmente $E l$ inútil (1911) y El roto (1920/2019), como propuestas de redención a partir de personajes de los bajos fondos, que entran en su obra con la lente de la ficción.

Otras novelas de ese ambiente se suceden durante el resto de la primera mitad del siglo XX: Vidas mínimas (1923/2020) de José Santos González Vera, El delincuente (1925/1974) e Hijo de ladrón (1951/1973) de Manuel Rojas, La viuda del conventillo (1930/2000) de Alberto Romero, La vida simplemente(1951) de Oscar Castro y la saga de las novelas "marginales" de Nicomedes Guzmán, publicadas entre 1939 y 1951. 
Sobre lo que denuncia esta literatura, Ana Gálvez Comandini (2013) postula que esta plantea la prostitución como una consecuencia social y económica del sistema construido por los gobiernos oligárquicos chilenos de la época. Concluye que "la prostitución vendrá a representar una forma más de sometimiento de los sectores populares a los designios del capitalismo” (p. 221). Gálvez usa los arquetipos junguianos para presentar cuatro personajes centrales de las historias prostibularias: el prostíbulo, la prostituta, la regenta y el cliente. El lugar es céntrico, cerca de los círculos del poder, pero no de donde vive la élite. A la sombra de estos íconos de poder y modernidad, surgirán barrios sórdidos, habitados por aquellos otros/as olvidados por el progreso y la ilustración.

Así, por ejemplo, describe ese escenario Alberto Romero (1935/1997):

Entre usinas y tugurios, las casas chatas asilaban un mundo extraño y pintoresco de obreros y prostitutas; de delincuentes de ínfima categoría y empleaditos de comercio; de jubilados y achacosos a los que el encarecimiento de la vida iba relegando al suburbio, donde la niña venida a menos ponía una nota de distinción triste cuando al caer la tarde se exhibía en el marco de la ventana penumbrosa con su cara maquillada y lamentable (p. 22).

La mirada de Ana Gálvez Comandini (2013) sobre la descripción de los prostíbulos en la literatura chilena es especialmente atinada: hostiles por fuera, acogedores por dentro, vagamente evocadores de una grandeza perdida que ni las prostitutas ni los clientes conocieron nunca, y con elementos que a lo largo de los años no cambian, pese a que los barrios circundantes se vuelven irreconocibles. La autora destaca que, con 30 años de diferencia, los burdeles de novela se mantienen casi idénticos, porque surgen del ideal decimonónico y del sitio que los autores y su público reconocen como antro de degradación material y espiritual:

Es curioso descubrir la similitud del relato de descripción del prostíbulo que hace Óscar Castro y Joaquín Edwards Bello, principalmente porque entre una y otra novela existe alrededor de 30 años de diferencia. Sin embargo, esto viene a confirmar que el imaginario de la prostitución subyace en la contemporaneidad de ambos escritores, y que si bien Edwards escribió primero, Castro, 30 años después no se quedó atrás, relatando desde los recuerdos de infancia la vida en estos sitios de infamia y dolor. En los relatos literarios, la representación del prostíbulo, en cuanto a espacio físico, tiene que ver siempre con la simulación de algo que no es (Gálvez Comandini, 2013, p. 229)

En la novela El roto, Joaquín Edwards Bello traza con precisión esa parodia de conquista que durante generaciones creó el embrujo del lupanar para los clientes:

Esas mujeres sin miedo ni delicadeza, hechas a todas las salvajadas, en roce con los más bestiales individuos, tenían la coquetería de la pasividad; fingían timidez para mostrar algo femenino. Incapaces de moverse y de hablar, sin ánimos para matar una mosca, fruncidas y rígidas, esperaban que fuesen a convidarlas para bailar, lo que hacían con la vista baja, el paso tímido y la cara compungida, llenas de remilgos y melindres. Era preciso un largo flirt para congraciarse con cualquiera de ellas (1920/2019, p. 61).

El crítico y columnista Héctor Soto pone la lupa en el carácter moralizante de estas narraciones, especialmente en El roto. En su artículo "Local y visita: El doble eje de Joaquín Edwards Bello" (2010), Soto muestra una dicotomía moral en la novela de Edwards Bello que es la opuesta a la que, en el momento de su publicación, pregonaba la burguesía ilustrada y bienpensante, y por la que el libro tuvo una recepción negativa y agresiva. El roto no muestra la podredumbre de los pobres, sino la corrupción de los ricos. Soto (2010) postula que la lección ética de El roto es la siguiente: es en lupanar donde crece el niño que se convierte en "el roto", donde se encuentra la posibilidad de redención moral de Chile: 
Si Chile tiene algún destino, cree Edwards Bello, es por los valores que puedan quedar en la base de la pirámide social -en los rotos, en las clases que la pobreza y el alcoholismo están disociando y destruyendo- y no por los que la indolencia y la codicia nacional hicieron desaparecer de la cúpula. Hay que decirlo: a diferencia de lo que hacía en las crónicas, en sus novelas Edwards Bello era sensible a la moral de la redención social. Querían enseñar, moralizar, redimir, salvar el mundo, y probablemente a este factor, más que a cualquier otro, se debe que no hayan terminado envejeciendo muy bien (p. 342).

Como puede apreciarse, Soto marca una diferencia entre el Edwards Bello de sus novelas (El roto y también El inútil, una crítica demoledora de la indolencia de la clase alta chilena), como fábulas con moraleja, y sus columnas, que son más descriptivas, menos "de tesis". No obstante, considero que hay dos diferencias más, que se intentarán explicar en el siguiente apartado: por un lado, los temas; por otro, la posición del autor ante lo que muestra, detalla y denuncia.

\subsubsection{Presencia en las novelas y ausencia en las Aguafuertes de Roberto Arlt}

En Roberto Arlt, el habitante solitario (1972), Diana Guerrero estudia los temas sociales en la obra arltiana y se detiene en el papel de la mujer como oprimida y víctima de una sociedad patriarcal y falocéntrica. En las novelas Los siete locos (1929/1986) y Los lanzallamas (1931/1968), Guerrero distingue a las mujeres casadas y las solteras que buscan marido como doblemente oprimidas por los roles asignados a su género en las primeras décadas del siglo XX. En ese entorno, Hipólita es la única que escapa a estos mandatos de su género al convertirse en prostituta y en una amenaza para las esposas burguesas. Ese mundo novelístico de Arlt está poblado por marginados trágicamente triunfantes, encabezados por Erdosain, el alter-ego del autor, que desprecia los valores burgueses, busca quebrar las cadenas de la mediocridad, se junta con criminales, estafadores, locos y malvivientes y sueña con un invento estrafalario que lo vuelva rico y lo redima.

Tania Diz (2016) enfatiza en esta visión radical del novelista y en la mirada de Guerrero: el personaje de la prostituta como una liberada, que Arlt presenta en sus novelas, no está presente en la visión más conservadora de la ciudad y sus personajes que en la misma época el autor describe en sus crónicas. Para Diz (2016), se presenta a Hipólita como

el único personaje femenino que tiene independencia como tal; los otros no son más que feminidades en contraposición a un varón que las define, usa, idealiza o desprecia. Hipólita, en cambio, desde afuera de la identidad pequeño-burguesa, pasa a ser una amenaza para el varón ya que no respeta los mandatos de género y, además, logra crecer como personaje al sacar provecho de los lugares que ocupa: sirvienta, esposa, prostituta (p. 30).

Además, la autora identifica al personaje más monstruoso en una novela plagada de monstruos: es Haffner, el rufián que atribuye a las prostitutas a las que oprime, humilla, tortura y estafa, la culpa de su propio estado:

¿En qué consiste su monstruosidad? En considerar que al explotar a las prostitutas, establece con ellas una relación de dominación que recrea el vínculo entre amo y esclavo propio del sadomasoquismo, incluso, mediante la inversión: es la víctima quien obliga al amo -el hombre- a humillarla (Diz, 2016 p. 32).

Encontramos en la novela misma el punto central de la perversión del opresor que alega su inocencia, un personaje mucho más oscuro que cualquiera de los que pueblan las aguafuertes melancólicamente costumbristas del autor:

Usted cree como el noventa por ciento que el cafishio es el explotador y la prostituta la víctima. Pero dígame: ¿para qué precisa una mujer todo el dinero que ella gana? Lo que no han dicho los novelistas es que la mujer de la vida que no tiene hombre anda 
desesperada buscando uno que la engañe, que le rompa el alma de cuando en cuando y que le saque toda la plata que gana, porque es así de bestia. Se ha dicho que la mujer es igual al hombre. Mentiras. La mujer es inferior al hombre (Arlt, 1929/1986, pp. 28-29).

Como puede comprenderse con lo presentado hasta acá, resulta notable que sea en una novela, y no en las crónicas de escritores de ambos mundos como Arlt o Edwards Bello, donde se encuentra el discurso del personaje novelesco en que plantea una verdad aparentemente demasiado cruda como para que la traten los novelistas y que, por lo tanto, pertenece a los relatos ciertos de la vida en las calles.

\subsection{La otra orilla: posibilidades y peligros de la no ficción}

Se han esbozado numerosas definiciones y listados de ingredientes de la llamada crónica, periodismo narrativo o periodismo literario. En el ámbito latinoamericano, la venezolana Susana Rotker (2005) traza su origen en la crónica modernista y distingue entre sus componentes la mirada personal, con elementos de ensayo y profusión de metáforas y comparaciones, la descripción de ambientes y la creación de personajes. Sus principales ejemplos son las crónicas de José Martí y Rubén Darío. En España, Albert Chillón (1999) prioriza en su análisis el "giro lingüístico" y la presencia del narrador en los hechos que relata. Estudia sobre todo a escritores europeos de no ficción como el polaco Ryszard Kapuscinski y la italiana Oriana Fallaci. Autores como Jorge Carrión y María Gómez y Patiño (2015) coinciden en que es un término aún en debate. Para Gómez y Patiño (2015), la literatura no logra un consenso sobre la definición de este género y, de hecho, parecen existir tantos tipos de crónicas como cronistas. Al respecto, puntualiza que "no deja de ser paradójico que el término Literary Journalism (Periodismo literario) se asocie como inevitable a la crónica, al tiempo que da cabida a un sinfín de fórmulas, estilos y características que resultan difícilmente encasillables" (Gómez Patiño, 2015, p. 160).

Respecto del periodismo narrativo o literario, en tanto, en el libro Periodismo narrativo, Roberto Herrscher (2012) plantea que, más allá de atenerse a hechos ciertos, personajes existentes, diálogos reales y observaciones efectivamente hechas, este puede entrar en las mismas profundidades y trabajar con estrategias narrativas, estructuras y estilos complejos, híbridos y que dialoguen con los clásicos en pie de igualdad con la literatura de ficción, la poesía y el teatro.

Sin embargo, la inmersión en la propia experiencia y la participación del autor en los hechos que narra requieren un nivel de apertura y sinceridad que hacia finales del siglo XX alcanzó la crónica latinoamericana. En la época de Arlt y Edwards Bello, el lugar para explicar qué estaba haciendo el cronista en los burdeles y cuál era la naturaleza de su relación con los personajes con los que se cruza es claramente la novela. Allí donde no entraba el "yo" del cronista que firmaba sus artículos en el diario, podía adentrarse el personaje inventado de fábulas, tanto las que denuncian los males de la sociedad como las que muestran la extrema podredumbre de los individuos.

En contraste con lo anterior, en Europa la entrada de la narración verídica como camino para mostrar en profundidad los problemas políticos, económicos, sociales y culturales se produce antes. En las décadas de 1920 y 1930, Manuel Chaves Nogales (1935) se adentra en la visión subjetiva de un torero (Juan Belmonte, matador de toros) para internarse con agudeza en una vida extrema signada por el peligro y la fama, y viaja a la Unión Soviética para mostrar las contradicciones de una revolución con dosis de crueldad y de ilusión, y pergeña su obra maestra, A sangre y fuego (1937), para mostrar las lacras de ambos bandos en la Guerra Civil Española. 
Al mismo tiempo, el catalán Josep Pla convierte en El cuaderno gris (1966/2013) un diario íntimo en un relato subjetivo y muy preciso de su tiempo, y en Grandes tipos (1958/1995) viaja por la convulsionada Europa de su tiempo y retrata a los grandes hombres de su país en un cuadro coral a la vez profundamente atemporal en su ambición y atado a su momento histórico en la visión de cómo cada uno relata una faz de su época. Es en este mismo tiempo, y movido por similares hechos históricos globales, que George Orwell combina viajes asombrosos, encuentros con personajes inolvidables y un ojo preciso para los grandes cambios históricos y las relaciones personales y de clase en libros como El camino de Wigan Pier (1937/2001), Sin blanca en París y Londres (1933/2015) y Homenaje a Cataluña (1938/2013).

\subsection{Limitaciones de la crónica, posibilidades de la novela}

Hacia finales del siglo XX, la nueva crónica latinoamericana alcanza finalmente este estado de "literatura de no ficción". El académico ecuatoriano Fernando Checa Montúfar (2016) pone el dedo en la llaga al señalar la característica fundamental de la crónica a partir de 1990:

La crónica es un género rebelde no solo por su carga de subjetividad (alguien que cuenta desde su mirada) contradictoria de la exigencia de "objetividad" del periodismo tradicional, sino sobre todo porque este tipo de periodismo se ocupa casi siempre de los personajes de la vida pública, de los grandes acontecimientos; mientras la crónica se rebela contra eso (Checa Montúfar, 2016, p.160).

No obstante, como hemos explicado ya, en la crónica publicada en periódicos de la primera mitad del siglo XX, tanto Arlt como Edwards Bello encuentran límites internos y externos para llegar al fondo de las lacras sociales, mentales y espirituales de sus pueblos.

Las limitaciones externas se relacionan con lo que se permite publicar en los diarios de la época. Como relata el historiador Eduardo Santa Cruz (2011), la propiedad de los medios y la casi totalidad de sus lectores pertenecen a la clase adinerada, y los cronistas saben hasta dónde pueden llevar la crítica, no ya del gobierno de turno, sino de la clase social a la que sirven los medios para los que trabajan. Décadas más tarde lo explicaron Noam Chomsky y Peter Hermann (2000) con su teoría de los cuatro filtros en Los guardianes de la libertad. Al respecto, resulta interesante que Edwards Bello clamaba por autores de ficción que contaran lo que los periodistas o los historiadores no podían: "En Chile, donde se escribe tanta historia, hasta llegar a no saberse nada, hacen falta muchos novelistas que nos digan algo de la vida íntima, o de la sub-historia” (Arlt, 2020, p. 20).

Por otro lado, los límites internos tienen que ver con lo que era concebible en los escritos de no ficción conocidos en América Latina en la época. Siguiendo la definición de crónica periodística heredada de la tradición española ${ }^{3}$, la no ficción debía limitarse a observaciones cazadas al vuelo, retratos a vuelapluma, conclusiones rápidas que pudieran comprenderse entre un sorbo de café y el mordisqueo de una medialuna o una marraqueta. Esto se debía al escueto espacio disponible en los periódicos y por las condiciones económicas en las que trabajaban, de las que a lo largo de su vida se había quejado Arlt (Edwards Bello, en cambio, gozaba del patrimonio heredado de su origen patricio).

3 En El estilo del periodista, Alex Grijelmo (2014) postula que la crónica toma elementos de la noticia, del reportaje y del análisis. La primacía del elemento noticioso lo distingue de los dos últimos, y de la noticia lo diferencia el hecho de que incluye una visión personal de quien la escribe. 
Esta limitación puede relacionarse a una concepción generalizada sobre los textos periodísticos, que advierte Gemma López Canicio (2017):

El objetivo inmediato de cualquier texto periodístico parece opuesto al de un texto literario: mientras que la literatura puede permitirse la licencia de modificar, incluso, hechos reales para construir historias artísticas y ficcionales sin perder su valor ni su objeto principal, cualquier modificación de la realidad en un texto periodístico no es considerada una ficcionalización y, por tanto, aceptada por el lector, sino que, por el contrario, se tacha como una falacia o mentira y el texto queda desacreditado. Esto ocurre porque el objetivo principal del periodismo, como en el caso de la historia, no es otro que dar cuenta de la realidad con la mayor precisión, objetividad y exactitud posible (p. 182).

La profundidad de la mirada, la complejidad de la construcción de personajes y, sobre todo, la autorreferencia y el cuestionamiento del lugar del narrador en su propio relato estaban destinados al espacio libre, creativo, de largo aliento de la novela. Por eso mismo produce tanto impacto en un lector actual encontrarse con un libro sobre la trata de blancas en la misma zona y la misma época de Los siete locos y de El roto, escrito con el estricto apego a la realidad, sin invención ni ocultamiento y, sobre todo, con un narrador participante que interpela y cuestiona a sus fuentes y se pregunta permanentemente por su propio papel en la historia que está contando. Esa es la osadía y la radical modernidad de El camino de Buenos Aires (1927/2008), de Albert Londres.

\subsection{Albert Londres y El Camino de Buenos Aires}

\subsubsection{El camino de Albert Londres}

¿Quién es Albert Londres? El académico norteamericano radicado en Francia John Bak (2015) compara su vida y su obra con la de su "casi" homónimo Jack London, y busca en las similitudes y diferencias la especificidad de este autor, el más famoso de los cronistas internacionales de no ficción de las letras galas. De hecho, el principal premio para el Grand Reportage francés se llama Prix Albert Londres. Bak (2015) define su compromiso ético, su estilo y sus temas, comparándolos con los de Jack London, de la siguiente forma:

Like London before him, Londres was heavily influenced by the naturalism that pervaded at the fin de siècle, and both writers experienced wars, exposed poverty and studied urban decay through a realistic and scientific lens. They shared not only a dislike for house styles but also a complete distrust of journalistic objectivity, demanding their editors and audiences alike to confer a level of confidence not always attributed to first-person reportages that read like a novel or a short story. Also like London, Londres felt that his mission as a writer was to be 'un éternel vagabond, obliged to 'dénoncer l'oppresseur, révéler les lieux d'oppression' and 'donner la parole à ceux qu'ils l'ont perdue' (p. 2).

Albert Londres nació en Vichy en 1884. En su juventud publicó tres libros de poemas y luego se especializó en un tipo muy personal y elaborado de reportaje periodístico que combina crónica de viajes, perfiles de personajes, acción dramática, análisis y contexto histórico de temas de alto impacto y un muy ágil estilo vinculado a la novela realista de denuncia social. Así relata Bak sus inicios, la primera crónica, en plena Primera Guerra Mundial, que lo hizo encontrar su voz y su estilo y lo posicionó como narrador literario:

On September 21, 1914, Londres filed his story, titled “Ils ont bombardé Reims et nous avons vu cela!”, for Le Matin, and it appeared on the front page. Many scholars of the French press identify his dispatch as one of the first examples of modern French reportage. 
The story, a first-person account of the bombing and near-destruction of the Rheims cathedral, is noteworthy in how its rallies its readers to the cause not through a gruesome, naturalistic portrayal of the deaths of French soldiers and civilians, but rather through a universalizing of the death of France as a nation rendered through the metonymy of the cathedral itself. Describing the cathedral in religio-anthopomorphic terms, Londres writes that it was "la majesté religieuse descendue sur la terre" (Bak, 2015, p. 4).

Desde entonces y hasta su temprana muerte en 1932, cuando el barco en el que viajaba por el mar de Indochina fue bombardeado (nunca se encontró su cuerpo), Londres publicó 20 libros que son, para los periodistas literarios, de viajes y de investigación de Francia, la piedra basal de su arte. En Dante no vio nada (1924/2012), por ejemplo, retrata las inhumanas condiciones de vida en los presidios militares franceses en ultramar. Más tarde, en Tierra de ébano (1929/2012), se interna en la degradación moral de los funcionarios coloniales de la Francia esclavista en África. En Pescadores de Perlas (1931/2012), en tanto, indaga en la vida miserable y peligrosa de los buceadores que arriesgan su vida en Ceilán para buscar los adornos de las madamas europeas. Estos son algunos de los libros en los que Londres, con una valentía inusitada, escupe en la cara de sus compatriotas las tropelías y desmanes que su propio gobierno y sus poderosas empresas multinacionales realizan por el mundo. El literato viajero traía a sus lectores parisinos la cara oscura de la grandeza colonial y poderío económico del que se ufanaban sus clases dirigentes. En $E l$ judío errante ha llegado (1930/2012), sigue por Europa del Este, el Mediterráneo y la Palestina en manos británicas el andar de los hebreos perseguidos por el antisemitismo y buscadores de su propia tierra soñada. Este último es tremendamente profético y permite entender los progroms, la persecución de los nazis y sus aliados en toda Europa y los conflictos que sucederán cuando lleguen a Israel los refugiados tras la Segunda Guerra Mundial.

La década de 2010 es la de la recuperación del periodismo literario de Albert Londres, con estudios como los de Bak (2015); Dow, Bak y Meuret (2015), y de la investigadora francesa Johanna Cappi (2021). En España su redescubrimiento se produce en paralelo con la republicación de los grandes textos de Manuel Chaves Nogales y la llegada al mercado del libro en español de las traducciones de las crónicas periodísticas de Walt Whitman, coincidiendo con los 200 años del nacimiento del gran poeta en 2019. Las obras completas de Londres comenzaron a publicarse en España precisamente en esa década, en tomos que contenían tres o cuatro de sus libros. Del otro lado del Atlántico, la editorial argentina Libros del Zorzal publicó en 2008 la obra El camino de Buenos Aires. Desde la década de 1930, este libro no se encontraba disponible en librerías de la ciudad cuyos bajos fondos pintó como pocos narradores y como ningún periodista había hecho.

\subsection{2. ¿Qué viene a buscar Albert Londres a Buenos Aires?}

El camino de Buenos Aires es el quinto de los 20 libros de crónica viajera de Londres, y el primero que el autor piensa desde el principio como libro y no como serie de reportajes a publicar en primer lugar en medios. Su estilo ya está consolidado, su forma de trabajar es más pulcra, su prosa más madura que en sus primeras obras. Por el tema, introduce el habla popular, la ironía, el humor. Podría tomarse ese tono de compadreo con los tratantes de blancas franceses como una burla o, peor aún, una expresión de racismo y machismo, de aprobar las expresiones ofensivas y las autojustificaciones de los rufianes. Sin embargo, en la lectura atenta del libro se nota que su falta de ataque frontal no es una expresión de estar de acuerdo ni de ser neutral ante violaciones a los más básicos derechos humanos como el tráfico de personas, la violencia física y psicológica, el abuso sexual y el secuestro. Más bien, es parte del desarrollado aparato escritural de Londres: confía en la inteligencia y perspicacia de sus lectores.

Lo anterior se expresa, por ejemplo, en la siguiente escena, donde invita a sus lectores a seguir sus pasos: 
Se trata de las Casa Francesa. No sean tímidos. ¡Síganme! Subamos juntos los cinco escalones, que quizá también sean reglamentarios. Llamemos a la puerta. ¿No se atreven? Llamo yo. ¡Qué hermoso timbre! ¡Claro, nítido, argentino! La cortina se mueve. No se escapen. Nos hacen pasar el examen. Nos aprueban. Podemos entrar. La puerta es ancha. Entremos, amigos, ¡ustedes tampoco han de ser unos angelitos! ¡Madona santa! Parece una parada de colectivo. Van a distribuir los números. Cinco sentados sobre el banco, tres sobre las sillas, cuatro de pie. Es demasiado. Vamos a otra parte. Déjense llevar. Sólo son cien metros. Toquemos el timbre. Pasamos brillantemente el examen. Entremos. (Londres, 1927/2008, p. 65).

En otra escena, la madama lo trata como a un distinguido cliente, y eso acrecienta la sensación de desagrado y repulsión, sin que el autor deba decir explícitamente lo que siente o cómo debe ser leído. En este momento, está hablando con un grupo de proxenetas:

- Hace unos minutos, tuve el placer de conocer a mademoiselle Ópalo. Me confió que en una semana había encendido cuatrocientas dos veces su lámpara, en la casita. —¿Ópalo? -dijo Cicerón-. ¿YY de quién es ese lote? —iAh! -dije yo-. Mío no es, ipor desgracia! —Me parece que es de Adrien -dijo Víctor. - Entonces, a cinco pesos el fósforo y cincuenta y dos semanas por año, aun cuando sólo tuviera a mademoiselle Ópalo, Adrien gana 1.489.410 francos en doce meses (Londres, 1927/2008, p. 69-70).

En esta no-ficción de Londres, el discurso de los proxenetas es casi idéntico al del personaje del rufián de la novela de Arlt. Lo que en el argentino era impensable ver reflejado en un texto periodístico, un relato de una conversación real donde participa con su propio nombre, aquí (¿será porque la escena transcurre en otro país, en otro idioma?) se produce en la crónica. En cambio, en autores actuales como Martín Caparrós (2017) o Juan Pablo Meneses (2004) este tipo de diálogo, sin intervención crítica del periodista, ahora se publica en la crónica latinoamericana.

El poner las escenas sin el juicio del narrador es algo insólito en las crónicas argentinas o chilenas de la época. El efecto es demoledor. Así concluye el discurso moralizante del criminal en El camino de Buenos Aires (1927/2008):

Sin nosotros, ¿qué hacen las mujeres? Fuman, beben, toman cocaína, se enamoran, pernoctan, ¡se casan entre sí! Estas últimas palabras produjeron una profunda indignación en los otros tres: -Así es -dijo Cicerón-. ¡Fíjese hasta qué punto puede llegar la depravación de estas mujeres! - No bien ganaron cuatro monedas, dejan de trabajar. Se quedan acostadas en medio de la mugre o se van de parranda. ¡Tienen veinte años y las juntamos ebrias de la vereda! En vez de comprar lencería, beben vinos blancos de Burdeos. Están sucias, tienen las uñas negras, el pelo grasoso. Enseguida pierden toda dignidad. Algunas incluso se agarran de los pelos. Son bocas sucias. Nosotros reemplazamos todo eso. Las tomamos a nuestro cuidado, las lavamos, las frotamos. Las vestimos decentemente. Les transmitimos el gusto por la ropa limpia. Las alejamos de las malas compañías (p. 72).

En el final del libro, luego de relatar su viaje desde Francia con los victimarios y sus víctimas engañadas, la llegada a Buenos Aires, el desengaño, la brutalidad, la sordidez, la desesperación. Solamente en la última página, Londres se dirige al lector y lo increpa:

Darán cátedra sobre aquello que debe hacerse, aquello que no debe hacerse, sobre el bien y el mal. Hablarán de lo que puede verse. Lo más escandaloso, escuchen bien, no es que el mal exista, ¡sino que se vea! (...) Mientras haya desempleo. Mientras haya jóvenes con hambre, con frío. Mientras no sepan qué puerta golpear para encontrar un sitio donde dormir. (...) Mientras dejemos que los rufianes tomen nuestro lugar y les llenen el plato. Pueden quemar sus casas, excomulgar sus cenizas, no habrán hecho sino fuego y grandes gestos. La responsabilidad es nuestra. No nos desentendamos de ella (1927/2008, p. 127). 
El valor de esta crónica de 1927 estriba en esta presencia radical del "yo" como representante del cuerpo del lector: "yo estuve allí por ti”, entre otros méritos de investigación acuciosa, presencia en los lugares donde sucede la acción hasta el grado de ponerse en peligro, cuidado en la precisión de los datos y la fuerza del estilo. Al mismo tiempo, hasta el mismo momento del final, que por eso adquiere tanta contundencia, destaca también la ausencia del "yo" como juez, como dedo acusador, como mirada moral.

Por lo tanto, la presencia de Albert Londres es como una cámara fija, que no subraya, pero que tampoco permite desviar la vista. Es una primera persona incómoda, porque nos representa. Al respecto de este tipo de primera persona, afirma Darío Jaramillo Agudelo (2011) en su introducción a su Antología de crónica latinoamericana actual:

Nos convencieron de que la primera persona es un modo de aminorar lo que se escribe, de quitarle autoridad. Y es lo contrario frente al truco de la prosa informativa (que pretende que no hay nadie contando, que lo que cuenta es "la verdad"), la primera persona se hace cargo, dice esto es lo que yo vi, yo supe, yo pensé (...) siempre hay un sujeto que mira y que cuenta. Que hace literatura (p. 22).

\section{Discusión}

Como hemos mostrado en el recorrido de este artículo, casi todos los escritores que cultivaron el periodismo y la literatura reservaban su pluma periodística a contar hechos precisos y relevantes, denunciar males de la sociedad y sus gobernantes, o entrevistar a personas de interés. El vuelo literario, la estructura creativa y la inmersión en el complejo espíritu de las personas y los tiempos lo buscaban en el reino de la ficción. Esto, hemos visto, se puede retratar en los trabajos de Edwards y Arlt. Estos discursos y la sórdida realidad donde se mezclan los dos extremos de la sociedad chilena y argentina de la época se pueden dar solamente bajo el amparo de la ficción, que esconde y atenúa la mirada del narrador.

En este punto, es relevante puntualizar que el propósito no es poner las novelas de Romero, D'Halmar o Edwards Bello en el mismo lugar de propósito, género y estilo de las de Roberto Arlt. Al respecto, connotados críticos como Ricardo Piglia (1973), Beatriz Sarlo (2007) y David Viñas (1997) han marcado la radical modernidad y extrañeza en la obra arltiana: no muestra a los perdedores y humillados como víctimas inocentes, sino como cómplices y muchas veces ejecutores masoquistas de su propia tragedia. Sin embargo, a los fines de este artículo, hay una verdad, una delicadeza en el detalle, una complejidad en la descripción de lo que es bello y horrible a la vez en las grandes novelas de ambos autores que falta en sus celebradas crónicas.

Lo anterior contrasta con el desarrollo de la crónica europea, como ejemplifica la prosa elástica y moldeable, y la construcción precisa y multifacética de personajes en la obra de Albert Londres. A él se le puede aplicar lo que López Canicio (2017) define como el personaje del "narrador-periodista":

El narrador adopta, entonces, la identidad del escritor de la obra y queda construido a su imagen y semejanza: se preocupa por justificar la información q ue aporta, interviene de forma activa en el relato, juzga y opina, apela al lector, se disculpa... Con este tipo de voz narrativa literaria, el autor trata de plasmar en su obra todo el conocimiento del caso en cuestión y, además, está muy interesado en que el receptor comprenda que todo ese conocimiento es fruto de un arduo proceso de investigación real, que contrasta como verdadera toda la información que el relato ofrece (p. 89).

Este es exactamente el tipo de búsqueda de lo literario en lo real, de construcción del personaje del narrador como distinto a la voz "neutra" del periodista informativo, e incluso la construcción de un relato que construye un mundo y lleva al lector a 
internarse en sus entrañas, que distingue al relato complejo de no ficción de la crónica breve, aun de las divertidas y lúcidas crónicas de Edwards Bello y Arlt. Lo que ellos buscaron en la novela -porque no podían sobrepasar los límites estrictos del artículo de diario-, Albert Londres lo armó con los mimbres de la realidad, y en el mismo territorio del burdel criollo donde sus pares del Sur saltaron a la novela. En este contraste radica, justamente, el aporte de rescatar el trabajo de Albert Londres, especialmente aquel situado en el Cono Sur. Como hemos visto, Londres "trae" una crónica desde Europa que, de alguna manera, adelanta lo que sería la crónica latinoamericana en la segunda mitad del siglo XX, probablemente influyendo en la crónica local.

\section{Conclusión: por qué la prostitución irrumpe en la crónica décadas después de que se extinguiera como lugar privilegiado en las novelas}

Las condiciones que permitieron que Albert Londres escribiera el gran relato de no ficción de la prostitución en el Cono Sur en la década de 1920 son varias. A continuación, arriesgamos algunas. En primer lugar, el proyecto general de su obra que lo llevó en dos décadas a los cinco continentes. En los casos de los cronistas de ayer (como Chaves Nogales, Pla, Orwell, Karl Krauss, Egon Erwin Kisch) y de hoy (como Caparrós, Leila Guerriero, Joseph Zárate, Juan Villoro, Josefina Licitra), es siempre en gran medida un esfuerzo, una ambición y un talento personal el realizar una obra que salga de los cánones usuales del periodismo al uso.

No obstante, más allá de las cualidades personales, Londres contó con una industria editorial, un entorno intelectual, un contexto mediático que permitía textos que cuestionaran y atacaran las ideas preconcebidas y auto-congratulatorias de su país en el terreno de la no ficción. La industria de los medios y las publicaciones periodísticas en formato de libro han sido durante muchos años reacias a discursos contrarios a los considerados "valores centrales" de la patria, sus instituciones y su clase dirigente, como constatan los historiadores chilenos Eduardo Santa Cruz y Gonzalo Peralta en las introducciones a los primeros dos tomos (18131884 y 1884-1932) de la Antología de la crónica periodística chilena (2017a; 2017b).

Por otra parte, como explican Patricia Poblete Alday (2019) en sus estudios de la crónica chilena, y Marcela Aguilar (2019) en su tesis sobre el desarrollo de la crónica en Latinoamérica, el formato, la extensión de los textos, la complejidad de los asuntos tratados, el estilo y el grado de crítica a los poderes establecidos permitido en el género de la crónica periodística durante casi todo el siglo XX impulsaron un tipo de textos como las Aguafuertes de Arlt o las crónicas de Edwards Bello. A finales del siglo XX y comienzos de XXI cobra auge la crónica en gran formato que cuestiona con datos duros, entrevistas en profundidad, viajes de descubrimiento y análisis de fuste los grandes temas del momento desde el periodismo narrativo. Es en la misma época que cronistas latinoamericanos como Martín Caparrós (2017), Juan Pablo Meneses (2004) y Pedro Lemebel (1996) se acercaron al tema de la prostitución.

Hay muchos otros temas donde la participación y el papel del cronista dificultan la construcción de una subjetividad desde la cual contar. Por otro lado, igualmente difícil es encontrar un sitio alejado del moralismo y del buenismo socialista. Futuros estudios podrían indagar en estas otras temáticas que ilustran el carácter de la crónica a lo largo de la historia.

El camino de la crónica no es la búsqueda de la prostituta soñada o deseada como mala, como buena, como víctima o como símbolo sino la de verdad, con todas sus contradicciones. Mas, es la búsqueda de una mirada posible entre todas las contradicciones del cronista. Esto es más complejo aún, porque prácticamente todos los cronistas y novelistas analizados son hombres. En esa 
doble búsqueda, se acudió a preguntas sobre las posibilidades y peligros de la novela basada en hechos reales y el relato de no ficción, de hechos efectivamente reales, y de la influencia francesa, tanto en la ficción como en la no ficción, en el Cono Sur de América. ¿Quién mira, quién juzga, quiénes son "los nuestros" y quiénes "los otros"?

\section{Agradecimientos}

Artículo traducido al inglés por Brian O'Halloran.

\section{Referencias bibliográficas}

Aguilar, M. (2019). La era de la crónica. Ediciones Universidad Católica de Chile.

Arlt, R. (1968). Los lanzallamas. Compañía General Fabril Editora (Trabajo original publicado en 1931).

Arlt, R. (1986). Los siete locos. Planeta (Obra original publicada en 1929).

Arlt, R. (2020). La química de los acontecimientos: Crónicas y columnas desde Chile (F. Reyes, Ed.; $1^{\mathrm{a}}$ ed.). La Pollera Ediciones.

Bak, J. (2015). Un voyage épistemique et esthétique de London à Londres: Journalisme littéraire et literary journalism face aux guerres. En M. Boucharenc (Ed.), Roman et reportage, XXe-XXIe siècles: Rencontres croisées ( $1^{\mathrm{a}}$ ed., pp. 50-57). Presses universitaires de Limoges.

Caparrós, M. (2017). El sí de los niños. En Lacrónica (pp. 144-170) Anagrama.

Cappi, J. (2021). Albert Londres, grand reporter et photographe en Terre d'ébène: Sur le colonialisme, la traite humaine et la construction du chemin de fer Congo-Océan (Le Petit Parisien, 1928) En Voyage et Scandale. Ed. Classiques Gariner. En prensa.

Carrión, J. (Ed.). (2012). Mejor que ficción. Crónicas Ejemplares ( $1^{\mathrm{a}}$ ed.). Anagrama.

Castro, O. (1951). La vida simplemente. Editorial Nascimento

Chaves Nogales, M. (1935). Juan Belmonte, matador de toros. Estampa.

Chaves Nogales, M. (1937). A sangre y fuego. Héroes, bestias y mártires de España. Ercilla.

Checa Montúfar, F. (2016). Pedro Lemebel: Revelación y rebelión en sus crónicas desde el margen. Palabra Clave, 19(1), 156-184. https://doi.org/10.5294/pacla.2016.19.1.7

Chillón, A. (1999). Literatura y periodismo, una tradición de relaciones promiscuas, ( $1^{\text {a }}$ ed.). Publicacions de la Universitat de Barcelona.

Chomsky, N., \& Hermannn, P. (2000). Los guardianes de la libertad. Propaganda, desinformación y consenso en los medios de comunicación de masas (C. Castells, Trad.). Crítica (Obra original publicada en 1988).

D'Halmar, A. (1902). Juana Lucero. Los vicios de Chile ( $1^{\text {a }}$ ed.). Imprenta Turín.

Diz, T. (2016). Roberto Arlt, el sexo y los monstruos. Revista Mora, 22(2), 25-44. 
Dow, W., Bak, J., y Meuret, I. (2015). De London à Londres: le journalisme littéraire de Jack et d'Albert. En M. Boucharenc (Coord.), Roman et reportage: Rencontres croisées $X X^{e}-X X I^{e}$ siècles (pp. 41-66). Presses universitaires de Limoges.

Dumas, A. (2018). La dama de las camelias. Norma (Obra original publicada en 1848).

Edwards Bello, J. (1918). La cuna de Esmeraldo (1 $1^{\text {a }}$ ed.). Librairie P. Rosier.

Edwards Bello, J. (1911). El inútil (1 $1^{\text {a }}$ ed.). Imprenta Barcelona.

Edwards Bello, J. (2019). El roto (O. Carvajal Muñoz, Ed.; 1 ${ }^{\text {a }}$ ed.). Publicaciones Universidad Alberto Hurtado (Obra original publicada en 1920).

Frey, J. A. (1999). A Victor Hugo Encyclopedia. Greenwood Press.

Gálvez Comandini, A. (2013). El imaginario de la prostitución en Chile: Literatura y figuras arquetípicas, 1902-1940. Cuadernos de Historia Cultural Revista de Estudios de Historia de la Cultura, Mentalidades, Económica y Social, 2, $220-251$.

Gómez Patiño, M. (2015). La primera crónica de Miguel Hernández: El nuevo periodismo (1936- 1939). Historia y Comunicación Social, 22(1), 159-172. https://doi.org/10.5209/rev_HICS.2015.v20.n1.49553

González Vera, J. S. (2020). Vidas mínimas. Pravana Books. (Obra original publicada en 1923)

Guerrero, D. (1972). Roberto Arlt, el habitante solitario (1 ${ }^{\mathrm{a}} \mathrm{ed}$.). Granica.

Herrscher, R. (2012). Periodismo narrativo. Cómo contar la realidad con las armas de la literatura. ( $1^{\mathrm{a}}$ ed.). Publicaciones Universidad de Barcelona.

Hugo, V. (2015). Los miserables (M. T. Gallego Urrutia, Trad.; $1^{\mathrm{a}}$ ed.). Alianza (Obra original publicada en 1862).

Jaramillo Agudelo, D. (2011). Collage sobre la crónica latinoamericana del siglo veintiuno. En Antología de crónica latinoamericana actual (pp. 11-50). Alfaguara.

Lemebel, P. (1996). Loco afán (1 ${ }^{\mathrm{a}}$ ed.). LOM.

Londres, A. (2012). Dante no vio nada. En Obras Completas, Vol. 2 ECC (Obra original publicada en 1924).

Londres, A. (2008). El camino de Buenos Aires. (A. Falcón, Trad.; 1ª ed.). Libros del Zorzal (Obra original publicada en 1927).

Londres, A. (2012). Tierra de ébano. En Obras Completas, Vol. 1 ECC (Obra original publicada en 1929).

Londres, A. (2012). El judio errante ha llegado (A. Cabezas, Trad.; $1^{\text {a }}$ ed.). Melusina (Obra original publicada en 1930).

Londres, A. (2012). Los pescadores de Perlas. En Obras Completas, Vol. 1 ECC (Obra original publicada en 1931).

López Canicio, G. (2017). Ficción en la novela de la no-ficción. Análisis del estatuto ficcional a partir del narrador. Impossibilia. Revista Internacional de Estudios Literarios, 13, 176-198. https://doi.org/10.32112/2174.2464.2017.154

Manuel, R. (1973). Hijo de ladrón. Círculo de Lectores (Obra original publicada en 1951).

Meneses, J. P. (2004). Sexo y poder ( $1^{\text {a }}$ ed.). Planeta.

Merino, R. (2014). Barrio República. Una crónica (1 ${ }^{\mathrm{a}}$ ed.). Ediciones Universidad Diego Portales.

Orwell, G. (2015). Sin blanca en París y Londres. Debate (Obra original publicada en 1933). 
Orwell, G. (2001). El camino de Wigan Pier. Penguin (Obra original publicada en 1937).

Orwell, G. (2013). Homenaje a Cataluña. Debolsillo (Obra original publicada en 1938).

Piglia, R. (1973). Roberto Arlt, una crítica de la economía literaria. Los Libros, 29.

Peralta, G. (Ed.) (2017a). Antología de la crónica periodística chilena. Volumen I. (1 ${ }^{\mathrm{a}}$ ed.) Editorial Hueders y Departamento de Periodismo de la Universidad Alberto Hurtado.

Peralta, G. (Ed.) (2017b). Antología de la crónica periodística chilena. Volumen II. (1 $1^{\mathrm{a}}$ ed.) Editorial Hueders y Departamento de Periodismo de la Universidad Alberto Hurtado.

Pla, J. (1958). Grandes tipos. Destino (Obra original publicada en 1958).

Pla, J. (1966). El cuaderno gris (D. Ridruejo \& G. de Ros, Trads.; 1ª ed.). Austral (Obra original publicada en 1966).

Poblete Alday, P. (2019). Crónica narrativa latinoamericana actual: los límites de lo real. Literatura y Lingüística (40), p. 95 - 112. https://doi.org/10.29344/0717621X.40.2062

Rojas, M. (1974). El delincuente. Zig Zag (Trabajo original publicado en 1925).

Romero, A. (2000). La viuda del conventillo. Editorial Andrés Bello (Trabajo original publicado en 1930).

Romero, A. (1997). La mala estrella de Perucho González. LOM Ediciones. (Trabajo original publicado en 1935)

Rotker, S. (2005). La invención de la crónica (1 $1^{\mathrm{a}}$ ed.). Fondo de Cultura Económica.

Santa Cruz, E. (2011). La prensa chilena en el siglo XIX. Patricios, letrados, burgueses y plebeyos (1 ${ }^{\mathrm{a}}$ ed.). Editorial Universitaria.

Sarlo, B. (2007). Escritos sobre literatura argentina (1 ${ }^{\text {a }}$ ed.). Siglo Veintiuno.

Soto, H. (2010). Local y visitante. El doble eje de Joaquín Edwards Bello. Estudios Públicos, 118. https://www.cepchile.cl/cep/site/ artic/20160304/pags/20160304095258.html

Vargas Llosa, M. (2004). The Temptation of the Impossible (J. King, Trad.; ${ }^{\text {a }}$ ed.). Princeton University Press (Obra original publicada en 2004).

Viñas, D. (1997). Trece recorridos con las novelas de Arlt. En R. Arlt, Obras Completas: Novelas. Losada.

Zola, É. (2015). Nana (M. P. Irazazabal, J. Escué, \& Editorial Planeta SPA, Trads.; $1^{\text {a }}$ ed.). Penguin Clásicos (Obra original publicada en 1880). 